\title{
Effectiveness of Resiliency Training in Improving Mother-Child Relationship in Mothers of Children With Mental Retardation

\author{
Taghi Hadizad ${ }^{1}$ Firoozeh Sajedi $^{2 *}$, Guita Movallali ${ }^{1}$, Pourya Reza Soltani ${ }^{3}$
}

1. Department of Psychology and Education of Exceptional Children, University of Social Welfare and Rehabilitation Sciences, Tehran, Iran

2. Neurorehabilitation Research Center, University of Social Welfare and Rehabilitation Sciences, Tehran, Iran.

3. Department of Epidemiology \& Biostatistics, School of Public Health, Tehran University of Medical Sciences, Tehran, Iran

Citation: Hadizad T, Sajedi F, Movallali G, Reza Soltani P. Effectiveness of Resiliency Training in Improving Mother-Child Relationship in Mothers of Children With Mental Retardation. Iranian Rehabilitation Journal. 2016; 14(3):171-178. https://doi.org/10.18869/nrip.irj.14.3.171

: https://doi.org/10.18869/nrip.irj.14.3.171

Article info:

Received: 01 May 2016

Accepted: 03 Aug. 2016

\section{Keywords:}

Resilience training program, Mother-child relationship, Mental retardation

\section{A B S T RACT}

Objectives: To investigate the effectiveness of resiliency training in improving the motherchild relationship between mothers and their children with mental retardation.

Methods: This study employed an experimental design (pre-test, post-test) with the control group. The statistical population consisted of 52 mothers and their educable and mentally retarded children (3-12 years old) who were kept at daily welfare agency centers in Babol city, Iran. The experimental group received resiliency training program in 12 sessions (70 mins for each session) while the control group received no intervention. The measurement tool consisted of the mother-child's relationship questionnaire. Data analysis was done using multivariate analysis of covariance at a significance level of $\mathrm{P}<0.05$.

Results: The post-test analysis showed a significant decrease in the exclusion of children, extreme support and the easy going nature of mothers in the experimental group; however, the acceptance rate of mothers increased significantly.

Discussion: It seems that the resiliency training program improves the mother-child relationship in the case of mothers and their mentally retarded children and hence, reduces the exclusion, extreme support, and being easy-going nature. This improvement may be due to the changing attitude towards disability and improvement in the skills and behaviors of mothers.

\section{Introduction}

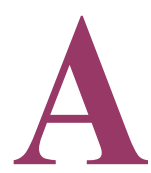

mong psychiatric disorders, mental retardation is the most common disorder in children and adolescents [1]. The prevalence of this disorder has been reported in $1-3 \%$ of the general population, and it is 1.5 times higher in boys than in girls. Educable and mentally retarded children with an IQ of 26-50 account for $2-3 \%$ of all the mentally retarded children [2].

The birth of children with mental retardation creates difficulties for family members, especially parents [3-5]. In the family institution, the fundamental role in maintaining the psychosocial balance is considered to be the mother's responsibility [6] because of the close relationship of the child with his or her mother.

* Corresponding Author:

Firoozeh Sajedi, MD

Address: Neurorehabilitation Research Center, University of Social Welfare and Rehabilitation Sciences, , Koodakyar Ave., Daneshjoo Blvd., Evin, Tehran, Iran. Tel: +98 (21) 22180099

E-mail: fisajedi@uswrac.ir 
Among other factors influencing the growth and development of child relations, mother's personality and her interaction with the child is critically important [7]. Mothers of children with mental retardation express a range of conflicting emotions $[8,28]$, which may vary from high acceptance to complete rejection [9]. The most common responses of mothers of children with mental retardation involve extreme protection [10], intolerance towards the child, denial of relationship, and rejection [11].

They sometimes extremely support their children, which prevent them from having an appropriate situation and independent activities or assume the child's capacity to be lower than their actual capability. On the other hand, they neglect their child and avoid providing the incentives for growth and healing $[12,13]$. Rejection by mothers occurs due to the lack of expecting progress, unrealistic expectations, leaving a child, and consigning him to the institution. Therefore, sometimes the parents accept the child's retardation completely, but most of the time the pressure from disability leads to the rejection of their child [14].

Mother-child relationship has an important role in the child being vulnerable or resilient [15]. Numerous studies have shown that the method of mother-child interaction such as rejection, over excessive control, and protection increases the possibility of symptoms of anxiety disorders in the childhood and emotional and behavioral disorders in adulthood [16-18]. It is noteworthy that the admission or rejection of child with mental retardation is dependent on the emotional adaptation of mothers.

Resilience is one of the normative concepts and constructs of interest, and the study of positive psychology perspective and adapts to the dynamic process of positive experiences is referred to as grim [19, 20]. It helps individuals to use positive feelings and emotions leaving behind negative experiences and return to the desired position [21].

Resilience is said to be the opposite of vulnerability, and parents who have high resiliency are closer to their child [22]. Horton and Walander (2001) believed that resiliency reduces stress and improves the quality of life of parents of children with disabilities and mental retardation [31]. It reduces stress and difficulties in parents that arise from the care of children with disabilities. White (2004) showed that resiliency program improves interpersonal relationships. In addition, it also reduces job stress and increases mental health of workers and teachers who interact with mentally retarded persons [23]. Gray (2002) concluded that programs based on resiliency, through their vision and belief system, bring changes in families with the autistic child leading toward a positive welfare [29]. A study by Shojaee et al. (2012) showed that resiliency training increased the well-being and also reduced the emotional distress in siblings of children with Down syndrome [30]. However, believed that the individual resiliency factors that led to the adaptation of parents of the child with mental retardation had been neglected.

Considering that the level of resilience in the parents of children with mental retardation is lower than the parents of normal children [24], they are required to intervene in this matter through programs that create resiliency and coping strategies. If mothers of children with mental retardation can increase their resiliency, they can also change cognitive schema about their child's disability and correct the common misunderstandings, prejudices, and stereotypes about mental retardation. This will also change their attitudes, behaviors, and skills to create an open, effective and flexible relationship that results in acceptance of their children by the parents [22]. So, in this study, we examined whether resiliency training has any effect on mother-child relation in the case of mothers of children with mental retardation.

\section{Methods}

In this quasi-experimental study, pre-test and post-test with a control group were used. Statistical population of this study consisted of mothers of educable mentally retarded children (IQ of 26-50) in Babol City, in 2014, who were referred to the daily welfare organization centers. The sample size consisted of 52 women who satisfied the inclusion criteria. They were selected based on their accessibility and randomly assigned to two groups, each group with 26 children. The inclusion criteria were: mothers of educable mentally retarded children (aged 3 to 12 years) and those who kept their children in day care centers.

The exclusion criteria were serious psychiatric disorders in mothers, consumption of psychotropic drugs, and participation in the same training programs. Ethical considerations included in this study are as follows: obtaining informed consent from mothers, observance of honesty and integrity, lack of cost and reliability of any possible damage, and confidentiality of all obtained information. At the first stage of the study, the pre-test analysis consisted of the mother-child relationship questionnaire. Next, the experimental group received 12 sessions ( 2 per week, each 70 minutes) of training resiliency, whereas the control group received no training. Then the intervention questionnaires were completed by both groups as post-test analysis. The resiliency training program designed by Shojaee et al. (2012) was used in this study [30]. The mentioned program was set based on the 
cognitive-behavioral therapy in a group. The content of the program was as shown below:

First session: Welcome and introduction of members;

Second session: Introduction to the process of association and the right way of thinking to make a proper connection;

Third session: Identification of problematic behavior and familiarity with the ways of dealing with problematic behavior;

Fourth session: Management of emotions and feelings and gaining the ability to switch over feelings;

Fifth session: Introduction to the concepts of stress and coping methods;

Sixth session: Anger management and methods of reducing and controlling anger;

Seventh session: Introduction to problem-solving procedures, training and job performance problem-solving process with examples and events real;

Eighth session: The objective and plans of life. Descriptive statistical techniques to estimate the prevalence, frequency, mean, standard deviation and inferential statistical techniques were used for multivariate analysis of covariance analysis.

The mother-child relationship questionnaire was prepared by Ross (1961) under the Center for Psychological Studies. This 48-item questionnaire is a self-report test with 4 subscales that include acceptance, extreme support, being easy going, and rejection. Each scale contained 12 questions. In phrases 1-39, the scoring was based on the Likert scale from "1" (completely agree) to " 4 " (completely disagree), and the phrases 40-48 were scored in contrast. The test reliability was obtained by Zamiri (2005) on 30 women from 0.71 to 0.78 [32]. In this study, to determine the reliability of the questionnaire, the test-retest method was used. The questionnaires of 17 mothers of children with mental retardation (non-participants) were completed after two weeks. The results showed that the internal consistency of Cronbach's Alfa for the questionnaire items was equal to 0.85 . Relatively high negative correlation was obtained between the scale of acceptance and extreme support, rejection, and being too easy going. The mean correlation coefficient was 0.83 .

\section{Results}

Fifty-two mothers of children with mental retardation participated in this study. The mean and standard deviation age of the mothers were $28.4 \pm 42.32$ years. The working mothers accounted for $21.15 \%$ of the total study population, and $78.85 \%$ were housewives. A total of $24.63 \%$ mothers had no consanguinity with their husbands. The mean and standard deviation of the age of children (55.75\% males and $44.25 \%$ females) were $1.38 \pm 5.2$.

As shown in Table 1, the mean scores of the experimental group in the acceptance component had increased, and in other components, it had reduced significantly in post-test in comparison with the pretest stage. This change was not observed in the control group. The Kolmogorov-Smirnov test was not significant in any of the

Table 1. Descriptive characteristics of the pre-test and post-test data in two groups.

\begin{tabular}{|c|c|c|c|c|c|}
\hline \multirow{2}{*}{ Group } & \multirow{2}{*}{ Variables } & \multicolumn{2}{|c|}{ Pre-Test } & \multicolumn{2}{|r|}{ Post-Test } \\
\hline & & Mean & Standard Deviation & Mean & Standard Deviation \\
\hline \multirow{4}{*}{ Experimental $(n=26)$} & Acceptance & 41.23 & 2.38 & 45.46 & 3.03 \\
\hline & Extreme support & 48.07 & 3.36 & 44.19 & 3.05 \\
\hline & Being easy going & 44.65 & 3.35 & 41.27 & 4.16 \\
\hline & Rejection & 37.81 & 2.93 & 34.58 & 3.2 \\
\hline \multirow{4}{*}{ Control $(n=26)$} & Acceptance & 41.34 & 2.096 & 41.61 & 2.77 \\
\hline & Extreme support & 47.31 & 3.32 & 47.07 & 2.74 \\
\hline & Being easy going & 45 & 3.9 & 45.03 & 3.87 \\
\hline & Rejection & 37.11 & 2.06 & 37.42 & 2.33 \\
\hline
\end{tabular}


Table 2. Comparison of post-tests in two groups with control of the pre-test effect.

\begin{tabular}{|c|c|c|c|c|c|c|}
\hline Source of Changes & Variables & df & $\mathbf{F}$ & $\mathbf{P}$ & Coefficient Effect & Statistical Power \\
\hline \multirow{4}{*}{$\begin{array}{l}\text { Experiment } \\
\quad(n=26)\end{array}$} & Acceptance & 1 & 29.44 & 0.000 & 0.39 & 1.000 \\
\hline & Extreme support & 1 & 91.97 & 0.000 & 0.66 & 1.000 \\
\hline & Being easy going & 1 & 113.73 & 0.000 & 0.71 & 1.000 \\
\hline & Rejection & 1 & 82.95 & 0.000 & 0.64 & 1.000 \\
\hline \multirow{4}{*}{$\begin{array}{l}\text { Control } \\
(n=26)\end{array}$} & Acceptance & 1 & 50.54 & 0.000 & 0.52 & 1.000 \\
\hline & Extreme support & 1 & 48.34 & 0.000 & 0.51 & 1.000 \\
\hline & Being easy going & 1 & 34.54 & 0.000 & 0.43 & 1.000 \\
\hline & Rejection & 1 & 55.54 & 0.000 & 0.55 & 1.000 \\
\hline Error & & 46 & & & & \\
\hline Total & & 52 & & & & \\
\hline
\end{tabular}

Iranian Rehabilitation Journal

variables; so the default of the normal distribution of data was approved. The Levine test for ensuring the homogeneity of variance was not significant in variables, so the variances were homogeneous.

As shown in Table 2, by controlling the pre-test effect, the post-test score of mothers in the experimental group in acceptance subscale is significantly higher than the mothers in control group $(\mathrm{P}=0.00)$.

The post-test scores of mothers in the experimental group in extreme support, being easy going, and rejection subscales were significantly lower than the mothers in the control group by controlling the pre-test effect $(\mathrm{P}=0.00)$.

\section{Discussion}

This study showed that resilience program training was effective in increasing maternal acceptance of children with mental retardation. The results of this study are consistent with the findings of Kaveh et al. (2012) [36]. They found that resiliency creates changes in attitudes, behavior and skills of mothers of children with mental retardation so as to accept their child's condition. The results of the present study are also consistent with the research of White et al. (2002) who found that resiliency training to families of dialysis patients led to a better relationship between the patients and their relatives [37].

Hall et al. (2003) believed that resilience could improve relations with others and lead to a happier relationship [33]. Thus, the process of resilience-based intervention tries to make the mothers of children with mental retardation well-adapted to the problems associated with mental retardation, as well as have friendly and open, effective and permanent relationship with their children, and become flexible in their roles. Resiliency helps them to have the ability to change the schema and attitudes toward the mentally retarded children till the mothers accept their child's mental and physical disabilities and have realistic and appropriate behaviors. It also helps the mothers to focus on their child's capabilities and abilities rather than their weaknesses, which in turn helps them to develop warm and intimate relationships with their children.

This study also showed that the intervention program resulted in a significant effect by reducing the rejection of the mentally retarded child by the mother. This is consistent with the findings of Gray (2002), who concluded that programs based on resiliency helped change the vision and belief system of families with autistic children [29]. Furthermore, according to the results of Horton and Wallander (2001) study, intrapersonal resiliency factors improve the quality of life of parents with children with disabilities and mental retardation and reduce stress and difficulties arising from the care of such children [31]. Shojaee et al. (2012) also found that resiliency training increased well-being and decreased the emotional distress [30]. Hosseini Qomi et al. (2011) found that training programs based on the resiliency in mothers of children with cancer increased mental health and quality of life [38]. Hagh Ranjbar et al. (2012) found that there is a significant positive correlation between quality of life and resiliency in mothers of children with mental retardation [39]. 
The present study also showed that resiliency training had a significant effect on reducing extreme support by the mother of the mentally retarded child. Lustig et al. (2000), Tarantino et al. (2013), and Basu (2004) found that resiliency increased levels of positive emotions, self-esteem and successful coping with negative experiences $[25,34,40]$. It also made one well adapted to the challenges and imparted a feeling of solidarity in person [25]. It can be said that resiliency is the ability to maintain the adaptive behavior when one faces insult and does well and has healthy expectations [26].

Hamill (2003) stated that the resilience reduction of risk factors and exposure to risk factors increase the capacity of coping with stress, while strengthening and enhancing self-esteem and self-efficacy [42]. In terms of Korhonen (2007), although resilience results out of personal attribute and people's experiences in the environment, humans are not the victims of their heredity or environment. People can be trained to learn some skills to increase their resilience capacity. People can change their reaction to stress and unpleasant events so that they can overcome the problems of the negative environment [22]. Therefore, resilience can help mothers of children with mental retardation to adapt to the crisis, have open relations with their children, and be in their flexible roles, effectively and permanently.

The present study also showed that resiliency training reduced the 'being too easy going' nature of the mothers of children with mental retardation. This finding is consistent with the studies of White et al. (2002), Neil and Dias (2001); Hamill (2003) [37, 42, 43]. Gray (2002) showed that resilience increased the welfare of families with autistic children by changing their vision and belief system [29]. McGraths (2000) also showed that the increase in resiliency causes people to learn various coping strategies and skills [41]. This finding can be interpreted in terms of resilience not only to deal with problems and adverse events but produce a flexible response to the pressures of daily life. Overall, it can be said that resilience can cause an individual to successfully overcome adverse events despite exposure to severe stress, and this results in improvement of his or her social competence and academic and communication skills [27].

\section{Conclusion}

The findings of this study showed that resiliency training program increased the mother-child relationship in the case of mothers of children with mental retardation and decreased the extreme support and being too easy going nature. The process of resiliency training based on interventions changed the cognitive schema to the difficulties in mothers for rearing a child with mental retardation. The resiliency programs also changed the attitudes, behaviors, and skills of mothers so that they can improve their relationship with their child [22].

It seems that mothers with high resiliency use more effective coping strategies in dealing with their everyday problems, and their strengthened individual capacities ensure more resistance in caring a child with mental retardation. They have greater flexibility in relation to their children and emphasize on the ability of children instead of their weakness and inability and accept their children's mental and physical disabilities. Based on the findings of this study, it is recommended that the clinicians and counselors, psychologists and all those who somehow interact with the families of children with mental retardation, need to consider various methods for improving the resiliency of the parents.

\section{Acknowledgments}

It is necessary to appreciate all mothers and their children, and staff of the Social Welfare Department of Babol city who cooperated in this study. This paper is extracted from the master thesis of Taghi Hadizad, Department of Psychology and Education of Exceptional Children, University of Social Welfare and Rehabilitation Sciences.

\section{Conflict of Interest}

The authors declared no conflict of interests.

\section{References}

[1] Summers J, Boyd K, Morgan J. Evaluating patients with intellectual disabilities and comorbid mental health problems. Psychiatric Annals. 2004; 34(3):215-20. doi: 10.3928/00485713-20040301-10

[2] Kaplan E, Sadock B. Synopsis of psychiatry. Netherlands: Wolters; 2007.

[3] Meadan H, Halle JW, Ebata AT. Families with children who have autism spectrum disorders: Stress and support. Exceptional Children. 2010; 77(1):7-36.

[4] Koydemir S, Tosun Ü. Impact of autistic children on the lives of mothers. Procedia-Social \& Behavioral Sciences. 2009; 1(1):2534-540. doi: 10.1016/j.sbspro.2009.01.447

[5] Abbasi S, Sajedi F, Hemmati S. The effectiveness of life skills training on quality of life in mothers of children with down syndrome. Iranian Rehabilitation Journal. 2014; 12(22):29-34.

[6] Koohsali M, Mirzamani SM, Karimlo M, Mirzamani MS. [Comparison of social adjustment in mothers with and with- 
out of educable mentally retarded daughter (Persian)]. International Journal of Behavioral Sciences. 2008; 2(2):165-72.

[7] Amir F, Hassanabadi H, Asghari Nekan SM, Tabibi Z. [The present study investigated the effects of play therapy based on child parent relationship therapy on improving the parenting styles (Persian)]. Journal of Family Counseling and Psychotherapy. 2012; 1(4):473-489.

[8] Boström PK, Broberg M, Bodin L. Child's positive and negative impacts on parents - A person-oriented approach to understanding temperament in preschool children with intellectual disabilities. Research in Developmental Disabilities. 2011; 32(5):1860-871. doi: 10.1016/j.ridd.2011.03.017

[9] Hallahan D, Kauffman J. Exceptional learners: An introduction to special education. $12^{\text {th }}$ ed. Philadelphia: Pearson Publication; 2010

[10] Tajeri B, Boheiraei AR. [The association of parenting stress, religious attitude, and knowledge with maternal acceptance for sons with mental retardation (Persian)]. Research on Exceptional Children. 2007; 8(2):205-24.

[11] Pinquart M, Sorensen S. Gender differences in caregiver experiences: An updated meta-analysis. Journals of Gerontology Series B: Psychological Sciences \& Social Sciences. 2004; 61(1):33-45.

[12] Hardman MM, Drow K, Eghen M. Psychology and education of exceptional children: Community, school and family, clinical, child [H. Alizadeh, K. Ghanji, M. Yousef Laviye, F. Yadeghari, Persian trans]. Tehran: Danzheh; 2002.

[13] Adib Sereshki N. [Children with special needs; Family counseling (Persian)]. Tehran: University of Social Welfare \& Rehabilitation Science; 2010.

[14] Kakavand A. [Psychology and education of exceptional children (Persian)]. Tehran: Roshd Publication; 2011.

[15] Schroeder CS, Gordon BN. Assessment and treatment of childhood problems: A clinician's guide. $2^{\text {nd }}$ ed. New York: Guilford Press; 2011.

[16] Muris P, Meesters C, van den Berg S. Internalizing and externalizing problems as correlates of self-reported attachment style and perceived parental rearing in normal adolescents. Journal of Child and Family Studies. 2003; 12(2):171-83. doi 10.1023/A:1022858715598

[17] Perry JA, Silvera DH, Neilands TB, Rosenvinge JH, Hanssen T. A study of the relationship between parental bonding, self-concept and eating disturbances in Norwegian and American College Populations. Eating Behaviors. 2008, 9(1):13-24. doi: 10.1016/j.eatbeh.2007.01.007

[18] Jakobsen IS, Horwood LJ, Fergusson DM. Childhood anxiety/withdrawal, adolescent parent-child attachment and later risk of depression and anxiety disorder. Journal of Child \& Family Studies. 2012; 21(2):303-10. doi: 10.1007/s10826-0119476-x

[19] Masten AS. Ordinary magic: Resilience processes in development. American Psychologist. 2001; 56(3):227-38. doi 10.1037//0003-066x.56.3.227

[20] Luthar SS, Cicchetti D, Becker B. Research on resilience: Response to commentaries. Child Development. 2000; 71(3):57375. doi: $10.1111 / 1467-8624.00168$
[21] Carle AC, Chassin L. Resilience in a community sample of children of alcoholics: Its prevalence and relation to internalizing symptomatology and positive affect. Journal of Applied Developmental Psychology. 2004; 25(5):577-95. doi: 10.1016/j. appdev.2004.08.005

[22] Moghadam K, Estaki M, Saadat M, Koshki S. [Development of a resilience fostering program against stress and its impact on quality of life components in parents of children with mild intellectual disability (Persian)]. Journal of Exceptional Children. 2012; 11(2):119-140.

[23] Noone SJ, Hastings RP. Building psychological resilience in support staff caring for people with intellectual disabilities Pilot evaluation of an acceptance-based intervention. Journal of Intellectual Disabilities. 2009; 13(1):43-53. doi: $10.1177 / 1744629509103519$

[24] Grøholt EK, Stigum H, Nordhagen R, Köhler L. Is parental sense of coherence associated with child health? European Journal of Public Health. 2003; 13(3):195-201. doi: 10.1093/ eurpub/13.3.195

[25] Basu D. Quality-of-life issues in mental health care: Past, present, and future. German Journal of Psychiatry. 2004; 7(3):35-43.

[26] Garmezy N. Resilience and vulnerability to adverse developmental outcomes associated with poverty. American Behavioral Scientist. 1991; 34(4):416-30. doi: 10.1177/0002764291034004003

[27] Khazaely Parsa F. [The relation between Resiliency, capacity to overcome difficulties, stubborn persistence and self-improvement (Persian)]. University of Tehran: Special Students Counseling Center; 2009

[28] Mansouri S, Pourmohammadreza-Tajrishi M, Taheri M, Mirzamani S M, Salehi M. [The Relation between Parental Anxiety and Parenting Practices in 12-18 Years old Male Students with Mild Mental Retardation (Persian)]. Journal of Rehabilitation. 2012; 12(4):48-56.

[29] Gray D E. Ten years on: A longitudinal study of families of children with autism. Journal of Intellectual and Developmental Disability. 2002; 27(3):215-22. doi: $10.1080 / 1366825021000008639$

[30] Shojaee S. [Designing the program of increasing resiliency and evaluation of it's effect on resiliency and psychologic well being of siblings of students with Down syndrome (Persian)]. [Phd Dissertation]. Tehran: Tehran University; 2012.

[31] Horton T V, Wallander J L. Hope and social support as resilience factors against psychological distress of mothers who care for children with chronic physical conditions. Rehabilitation Psychology. 2001; 46(4):382-99. doi: 10.1037/00905550.46.4.382

[32] Zamiri R. [Evaluation of relation between child delivery type and child- mother affective relationship in preschool girls in Mashhad City (Persian)] [MA Thesis]. Tehran: Roodehen Branch, Islamic Azad University; 2005.

[33] Hall DK, Pearson J, Reaching IN. Resilience-giving children the skills to bounce back [Internet]. 2003 [Cited 2003 Nov 1]. Avilable from: http://www.reachinginreachingout. com/documents/Voices_for_Children_Report_-_Resilience_ Nov_2003.pdf 
[34] Tarantino B, Earley M, Audia D, D'Adamo C, Berman B. Qualitative and quantitative evaluation of a pilot integrative coping and resiliency program for healthcare professionals. EXPLORE: The Journal of Science and Healing. 2013;9(1):447. doi: 10.1016/j.explore.2012.10.00

[35] Korhonen, M. Resilience: Overcoming challenges and moving on positively. Ottawa: National Aboriginal Health Organization; 2007.

[36] Kaveh M, Alizadeh S, Delavar A, Borjali A. [Designing the resiliency increasing program against stress and its effect on quality of life of parents with mild mental retarded children (Persian)]. Iranian Journal of Exceptional Children. 2011; 15(2):119-140.

[37] White N, Richter J, Koeckeritz J, Lee Y, Munch KL. A crosscultural comparison of family resiliency in hemodialysis patients. Journal of Transcultural Nursing. 2002; 13(3):218-27. doi: $10.1177 / 10459602013003011$

[38] Hosseini Qomi T, Ebrahimi Ghavam S, Oloumi Z. [The effectiveness of resiliency training on quality of life of mothers of 10-13 years old children with cancer in Emam Khomeini hospital (Persian)]. Journal of Clinical Psychologic Studies. 2011; 1(1):77-100.

[39] Hagh Ranjbar F, Kakavand AR, Borjali A, Bermas H. [Resiliency and life quality in mothers of children with mental retardation (Persian)]. Journal of Health Psychology. 2011; 1(1):177-187.

[40] Lustig DC, Rosenthal DA, Strauser DR, Haynes K. The relationship between sense of coherence and adjustment in persons with disabilities. Rehabilitation Counseling Bulletin. 2000; 43(3):134-41. doi: 10.1177/003435520004300302

[41] McGrath, H. The Bounce Back! Resiliency program: A pilot study. Paper presented at: The Annual Conference of the American Educational Research Association; 2000 April 2428; New Orleans, Louisiana, USA.

[42] Hamill, SK. Resilience and self-efficacy: the importance of efficacy beliefs and coping mechanisms in resilient adolescents. Colgate University Journal of the Sciences. 2003; 35:115146.

[43] Neill JT, Dias KL. Adventure education and resilience: The double-edged sword. Journal of Adventure Education \& Outdoor Learning. 2001; 1(2):35-42. Available from: doi: $10.1080 / 14729670185200061$ 
